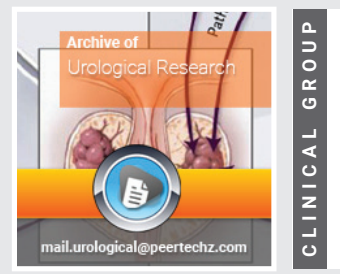

\title{
Chakras and energy alterations in patients with oligospermia
}

\section{Huang Wei Ling*}

Infectious Diseases Specialist, General Practice, Nutrition Doctor, Acupuncture and Pain Management Specialist. Medical Acupuncture and Pain Management Clinic, Franca, São Paulo, Brazil
Received: 09 March, 2020

Accepted: 02 April, 2020

Published: 03 April, 2020

*Corresponding author: Dr. Huang Wei Ling, MD, Rua Homero Pacheco Alves, 1929, Franca, São Paulo, 14400-010, Brazil, Tel: (55 16) 3721-2437; Fax: (55 16) 3702-8540; E-mail: weilingmg@gmail.com

Keywords: Oligospermia; Acupuncture; Auricular acupuncture; Chakras; Energy; Traditional chinese medicine; Homeopathy; Crystal-based medications

https://www.peertechz.com

\section{Abstract}

Introduction: Oligospermia is a male fertility problem characterized by a low sperm count. In Western Medicine, the causes of male sterility are mostly unknown. According to Traditional Chinese Medicine (TCM), oligospermia stems from Kidney deficiency.

Purpose: To demonstrate which are the chakras and energy alterations leading to oligospermia and how can we treat it.

Method: Two case reports. The first, C.X., a 29-year-old male, was diagnosed with non-obstructive oligospermia and second-degree left testicle varicocele. The seminal analysis found two spermatozoa per ml (6/4/2007). The TCM diagnosis was Yin/Qi Kidney Deficiency and Heat retention. The second patient named R, a 35-yearold male. He was trying to have a baby for three years without success. He was diagnosed with oligospermia (12 million per ml). The patient and his wife started treatment with Clomiphene, and after three months, the results showed less sperm than the first test (11 million per ml). A first IVF was done, with negative results. The couple searched for an energy-based treatment. He was diagnosed with Kidney Yin and Yang deficiency, Qi deficiency, Blood deficiency, and Heat retention. He received chakras measurement, with the use of radiesthesia. The result showed that on a scale from 1 to 8 , the patient's chakras were measured in the level 1 (the minimum). Both patients were treated with Chinese dietary counseling, auricular acupuncture, and apex ear bloodletting. The second patient received crystal-based medication and homeopathy.

Results: In the first case, after three sessions, another Vitro fertilization procedure showed a surprising increase in spermatozoa (from 2 to 20 million per ml). His wife became pregnant after IVF procedure. The second patient couple was able to achieve a natural pregnancy within a month of treatment, not requiring the use of IVF. The woman was treated.

Conclusion: There are energy alterations and chakras energy deficiencies in patients with oligospermia and the treatment on the energy level are important to achieve good results.

\section{Introduction}

A man with normal fertility has 15 million to over 200 million sperm per millimeter of semen. Oligospermia is defined as any amount lower than 15 million [1-3].

According to Western Medicine, oligospermia does not make the man sterile but diminishes the possibilities of conceiving naturally [1-3].

In Western Medicine, oligospermia can be caused by varicocele, defined as vein swelling draining the testicle, influencing sperm production and health. The use of some medications, genetic conditions, hormonal imbalance (low testosterone, high prolactin levels) can cause varicocele [4].
In Traditional Chinese Medicine (TCM), oligospermia is one of the causes of male infertility. The main causes of male infertility in TCM are:

(a) Constitutional kidney weakness;

(b) Overworking;

(c) Overexertion;

(d) Excessive early-age sexual activity;

(e) Cold liquids and food with Cold energy, dairy products, and greasy food [5-7].

Traditional Chinese Medicine and other ancient medical tools appeared to be effective in literature [5-7]. 


\section{Purpose}

To demonstrate which are the chakras and energy alterations leading to oligospermia and how we can treat it. Also, to demonstrate how a treatment based on ancient medical theories and tools may be beneficial, safe and a rapid method to treat patients with oligospermia.

\section{Methods}

The methodology of this study was based on the observation of two case reports of patients with oligospermia, developed in two different contexts and treated almost equally.

The first patient was treated specifically with the use of systemic acupuncture, auricular acupuncture associated with apex ear bloodletting and Chinese dietary counseling, while the second patient received the same treatment, associated with chakras measurement, and medication for replacement of chakras energy with homeopathy and crystal-based medications.

\section{First case report}

The case in question is a 29-year-old man with a history of one year of difficulty conceiving a child. His diagnosis was non-obstructive oligospermia and second-degree left testicle varicocele. His diagnosis in Traditional Chinese Medicine was Yin and Qi Kidney deficiency with Heat in the Gallbladder. This diagnosis was made on the basis of clinical history and physical examination.

The seminal analysis found only two spermatozoa (6/4/2007), while the normal count is 20 million per milliliter. A post-surgical analysis after a microsurgical correction of the varicocele (10/8/2007) detected oligospermia. In vitro fertilization, a right testicular micro-dissection showed a regular quantity of immobile spermatozoa. The normal quantity of mobile spermatozoa is greater or equal to $50 \%$.

Figures 1 and 2 are two cross-sections of a biopsy of one tubule of the testis. The former shows a normal condition and the latter the subject's biopsy. In Figure 1, the germ cell maturation begins in the seminiferous tubules from the basal toward the lumen.

There are germ cells in different stages of maturation and Sertoli cells. Spermatogonia are intermediary male germ cells in the production of spermatozoa. They are located in the basal compartment and can be observed through the round and hyperchromic nucleus in this region.

The vast majority of the other cells observed in the seminiferous tubules and that goes toward the lumen corresponding to the primary spermatocytes. Also, in the basal compartment, there are Sertoli cells with their elongated and lighter nuclei, also known as sustentacular cells.

The secondary spermatocytes are rarely observed in the human tissue because their half-life is short and soon goes on to the second meiotic division to form the spermatids that convert themselves into the spermatozoa through a series of metamorphic phases. One of the methods used by pathologists to evaluate the alterations in the gametogenesis is to establish the relation between the germ cells and the Sertoli cells counting 30 tubular sections. The normal relation is 13 germ cells to one Sertoli cell in a young adult. A normal tubular section has around 10 to 12 Sertoli cells, and almost half of the germ cells of a normal tubule section should be in the spermatids stage.

In Figure 2, in the patient's biopsy amounts of Sertoli cells is normal but there is an evident reduction of numbers of spermatids, and we practically cannot perceive the spermatozoa in most of the sections observed.

The patient was treated with Chinese dietary counseling, auricular and systemic acupuncture, the systemic acupuncture points used were: CV4, KI 3, CV12, SP 6, ST 36, GB 34, GV20, LR 3, HT 7, LU 7, PC 6 and Extra 5.

The auricular acupuncture points used were: Shen men, Kidney, Liver and Gallbladder; Spleen; Lung point, internal and external genitals and endocrine point.

The Chinese Dietary counseling that both patients received was: to avoid dairy products, coffee, and soda because these are the main kinds of food that cause kidney insufficiency. He was advised to avoid chocolate, fried food, eggs, honey, alcoholic beverages, and coconut because these are the main kinds of food that cause Heat on the Gallbladder meridian. Dietary sugglished in March 2019 [8].

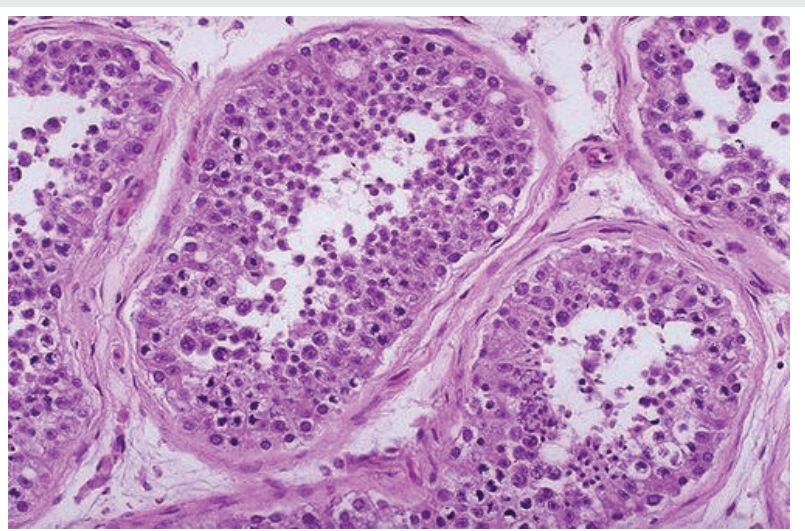

Figure 1: Normal Testis Biopsy.

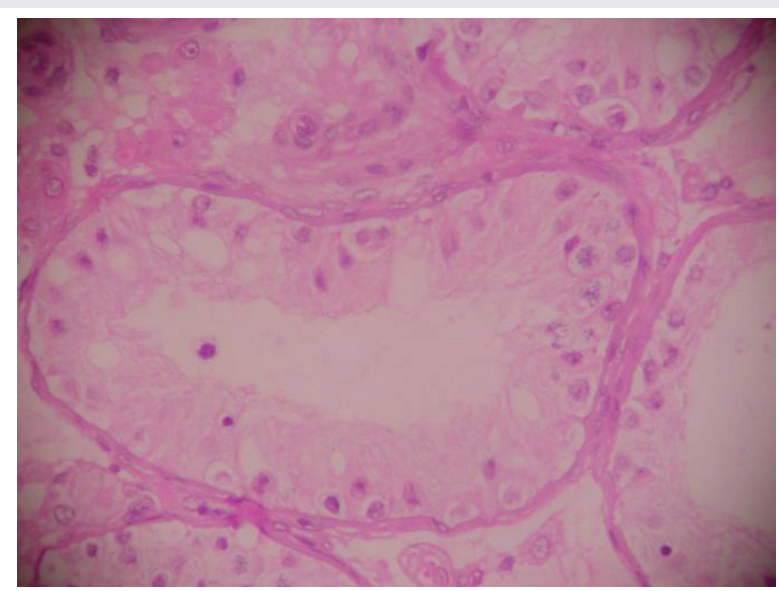

Figure 2: Histological condition compatible with the cessation of maturation of spermatogenesis at the level of spermatids 


\section{Results}

In the first case, the patient had a total of five sessions but after only three he went to do another in vitro fertilization procedure which showed a surprisingly greater quantity of spermatozoa (from 2 to 20 million per $\mathrm{ml}$ ). Attempts were made to fertilize 15 of his wife's ova and two were successful, but she became pregnant with one of them, giving birth to a baby girl, shown in Figure 3.

On the case of the second patient, on May 22, 2019, they found out she was pregnant naturally, without using IVF. After the exams, she confirmed, and the baby was born in January 22nd of 2020, a baby girl, as shown in Figure 4.

\section{Discussion}

\section{Western medicine management of oligospermia}

Having a low sperm, count can influence several aspects of life, not only fertility. For example, a study developed by Robert McLachlan, entitled Approach to the Patient with Oligospermia, showed that a man with low sperm count is more likely to develop testicular and prostate cancer later in life [4].

Western Medicine recommends life changes that can positively influence sperm count, such as weight loss, avoid hot baths, quitting cigarettes and managing stress may be helpful.

In Western medicine, it is also recommended the use of anti-inflammatory, antibiotics, pituitary stimulants and prolactin lowering can have great results.

Varicoele is defined as enlarged veins in the scrotum, what disrupts the blood flow from the testicles, causing higher temperatures of the testicles. Any increase in temperature can negatively affect sperm production.

On the case reports described, both patients performed treatment for varicocele. Unfortunately, on their cases, the treatment did not result in natural pregnancies.

\section{The tree metaphor}

The reasoning the author used to treat the patients was started during the treatment of one specific patient in 2006 . This patient was a 70-year-old patient, who reported pain in the legs and was diagnosed with Kidney-Yang deficiency, according to TCM. He received treatment with Chinese dietary counseling, acupuncture and auricular acupuncture associated with apex ear bloodletting $[8,16]$.

With the treatment done, the pain in the legs diminished and the patient was submitted to an interview after the treatment. In this interview, 30 days after the treatment, the patient revealed his eye pressure had also lowered, as his ophthalmologist confirmed. During the treatment, he had not reported to be treating glaucoma in the last 40 years with no improvement of his condition. With the treatment performed, his pressure lowers from $40 \mathrm{~mm} \mathrm{Hg}$ to $17 \mathrm{~mm} \mathrm{Hg} \mathrm{[8-16].}$

This unusual case became the cornerstone of the author's studies in the field, trying to comprehend how the treatment focused on the root of the problem could treat different diseases and symptoms simultaneously and using the same methods [8-16].

This interesting case became a cornerstone for the development of the metaphor of the tree, first present on the article entitled Why do Patients Still Catch Hospital Infections Despite the Practice of Infection Prevention and Control Programs? . This metaphor proposes a scheme for better comprehension of the differences between Western and Traditional Chinese Medicine reasoning.

The tree, exposed in Figure 5, has a trunk with several branches. Each branch represents one medical specialty and each leaf coming out of each branch represent the symptoms and diseases of each specialty. The leaves and the branches

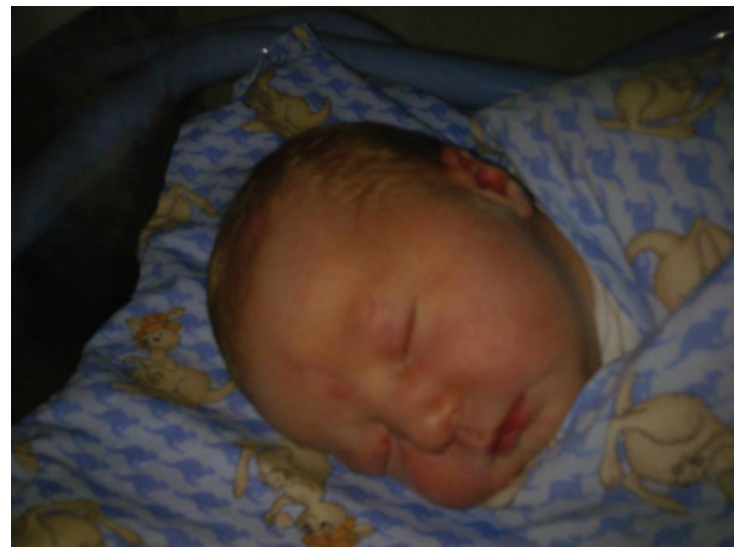

Figure 3: Baby born from Case Report 1.

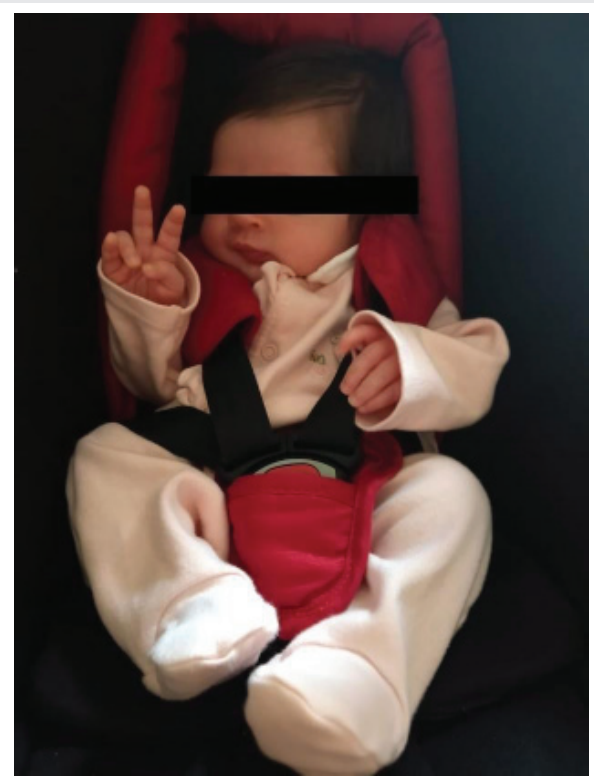

Figure 4: Case Report 2 - Baby girl born in January 22nd 2020.

are the visible part and the object of study and practice in the western medical profession. The focus is to treat each leaf in each specialty. The treatment proposed by the author aims to treat all the tree, through the root to reach a "health leaf" [816]. 
In this root, there is the energy that when balanced can generate health to the whole tree. The reason of this study is to address which are the energy alterations present in the root level, responsible for oligospermia [8-16].

\section{Traditional chinese medicine basics}

To understand the energy part in the health of the body, the author searched ancient medical traditions, like Traditional Chinese Medicine. Traditional Chinese Medicine comprehends diseases and symptoms as reflexes of imbalances in the energy flow [10-16].

Everything in the world is formed by energy, including the human body. Traditional Chinese Medicine considers that different energies inside the body have to be maintained in balance for achieving a state of health. These energies are Yin, Yang, Qi and Blood (Figure 6), and different aspects and behaviors can influence the body, like emotions, diet and external factors [10-16].

The body has energy meridians, linked to the Five Elements Theory, with massive organs, which have a dynamic balance in the body. When they are imbalanced, diseases are formed. Yin and Yang energies form these organs and their imbalance will influence the state of health of person [10-16].

\section{Yin and yang}

According to the Five Elements and Yin and Yang theories, the functioning of all energy meridians is interlinked. Therefore, if the Spleen is imbalanced, it will cause a decrease in the absorption of nutrients, leading to a reduction in the formation of Blood, and leading to the malnutrition of the other massive organs [17-19].

This malnutrition will lead to decrease in Yin and Yang energy (Figure 7), produced by the Kidneys, and a decrease in the energy of the Liver, responsible for energy distribution. Without energy to circulate properly in the body and blood vessels, Blood stasis and Qi stagnation can occur [17-19].

To diagnose energy imbalances, the patient completes the following questionnaire. It is important to ask about the items described in Table 1 [15-16].

\section{Chakras and crystal-based medications}

The chakras' concept, also already presented by the author in several other articles [8,13-16], appears in the Ayurveda medical theories, as well as in yoga theories. Chakras are main points of energy concentration. There are seven main chakras present in the body and their relationship among themselves is extremely important for the body's health [20-21].

The chakras correspond to the Five Elements within the Five Elements Theory, as exposed in limited trials in the literature. Many ancient medical scholars believe the five elements theory and the chakras' theory can connect. One example is entitled The Geometry of Emotions: Using Chakra Acupuncture and 5-Phase Theory to Describe Personality Archetypes for Clinical Use, the author links using chakras measurement with the principles of Traditional Chinese Medicine, described by the author in other articles, to comprehend the influence of a weakened energy in the chakras in the other systems of the body. Although this article is focused in personality archetypes linked to the chakras, it establishes a relationship between the Five Elements Theory and the seven chakras, in the same way as proposed by the author in previous articles [20].

As there are seven chakras and five elements, the seventh chakra is ruled by the first (Wood or Liver), and the sixth chakra is ruled by the second (Water or Kidney). The fifth chakra is ruled by Earth (Spleen-Pancreas), the fourth is ruled by Air, or Lung, the third is ruled by Fire or Heart. The second is ruled by Water or Kidney and the first chakra is ruled by Wood or Liver, as shown in Figure 8.

Using the chakra centers measurement was previously analyzed by George Washington, in the article entitled The Scientific Basis of Integrative Medicine. In the article, the author describes the pineal gland as a connection between the environment and the body systems, comprehending the chakras' system as an extension to the body's working systems [21].

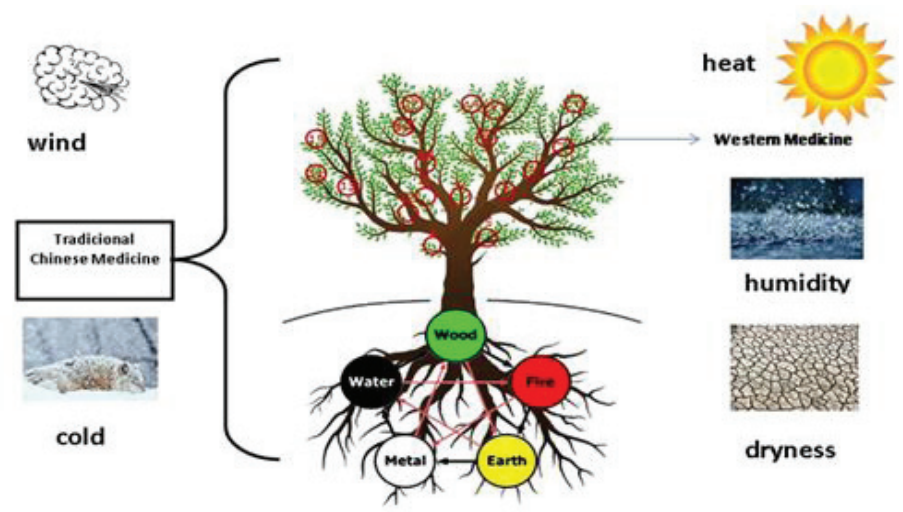

Figure 5: Schematic Drawing of the Views of Western and Traditional Chinese Medicine.

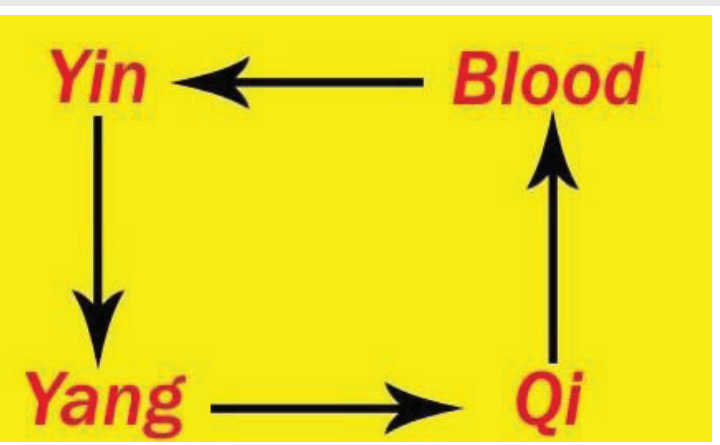

Figure 6: Yin, Yang, Qi, and Blood.

The second chakra is responsible for reproduction, normal production of sperm and eggs, it all depends on the energy of this specific chakra. However, when performing treatment, it is important to consider that the chakras are part of a dynamic balance, to replenish the energy of one chakra is necessary to 
replenish and rebalance the energy of all the seven chakras (or five elements). This is why the second patient passed through a procedure of radiesthesia, and then, treatment with homeopathy and crystal-based medication.

Traditional Chinese Medicine has different tools for measurement of the energies, with the use of physical examination. The radiesthesia procedure, even though is a part of Ayurvedic medicine, is important for measuring the energy of the patients easily, as well as helping the patient that is not familiarized with Traditional Chinese Medicine to better understand the diagnosis. With the use of this tool, it is possible to integrate more, bringing the results for the comprehension of Western medicine.

\section{Ancient medical tools and infertility}

The origin of reproductive issues, according to TCM, is the Kidney meridian. According to TCM, the Kidney is responsible for storing the essence of the body and controlling reproduction. The Kidney energy influences the Blood energy, when the Kidney energy is sufficient it nourishes the uterus, creating appropriate environment for implantation [23].

The treatment performed had the major goal of rebalancing the energy of the patients.

Several studies agree with the effectiveness of acupuncture in reproductive health, including the article, Acupuncture Treatment for Fertility, from Jihe Zhu. "Acupuncture as a treatment for infertility shows remarkable results both in men and women. Acupuncture can be considered a successful treatment in restoring fertility in the patients, by improving the sperm quality and ovaries function and balancing the endocrine system and hormones." [22].

Acupuncture is recognized as a medical specialty in Brazil since 1995 by the Federal Medical Council [10-16].

\section{Arndt-schultz law}

Patients with low sperm count usually have low energy of the Kidney, and low energy of the chakras. Therefore, all attempts to rebalance and replenish the energy of this type of patient have to be done, and all treatments that would harm the vital energy have to be avoided [10-16].

According to the Arndt-Schultz law (Figure 9), all drugs in high concentrations cause a reduction of vital energy, worsening the Kidney energy responsible for the production of sperm, besides reducing the energy of the other organs [10-16].

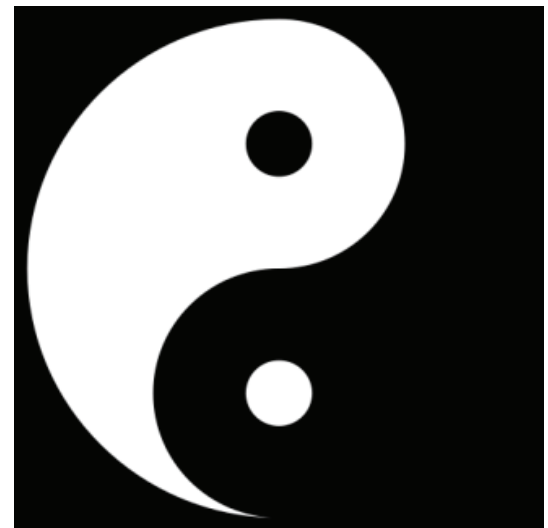

Figure 7: Yin and Yang.

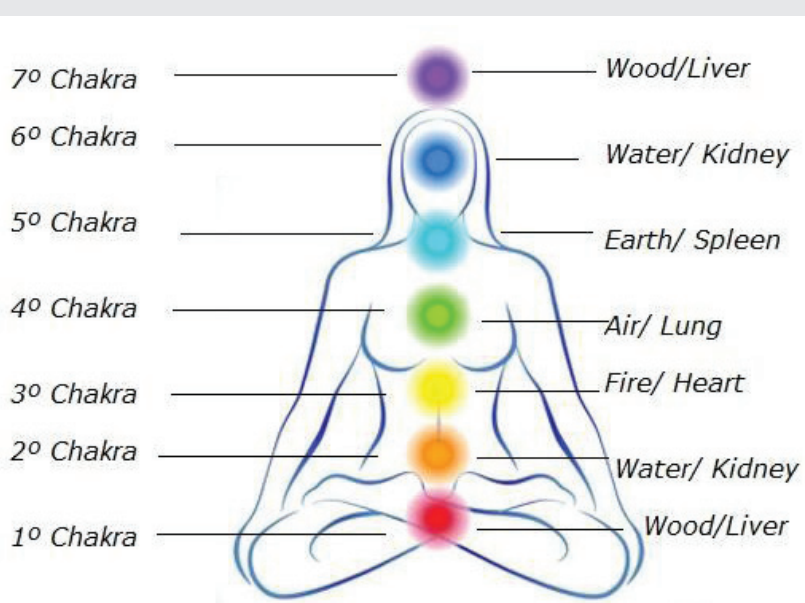

Figure 8: Chakras Energy Correspondence.

The choice of using homeopathy and crystal-based medication (high-diluted medications) was based on the idea of fortifying the energy of the patient that was already low.

It is important to treat both parents that have weakened energy, to guarantee a healthy pregnancy and a healthy baby [10-16].

Homeopathy is recognized as a medical specialty in Brazil since 1985 by the Federal Medical Council.

\section{Yin and yang metaphor of western and traditional chinese medicine}

To treat patients with oligospermia in a more effective way, the physician must comprehend the importance of the different

Table 1: How to Diagnose Yin, Yang, Qi, Blood and Heat Retention Imbalances?

\begin{tabular}{|c|c|c|c|c|c|}
\hline Question & $\begin{array}{l}\text { Does the patient have a } \\
\text { daily bowel movement? }\end{array}$ & $\begin{array}{c}\text { Does the patient have } \\
\text { excessive sweating } \\
\text { during the day? }\end{array}$ & $\begin{array}{l}\text { Does the patient feel cold in } \\
\text { the extremities of the body? } \\
\text { (Cold feet or hands) }\end{array}$ & $\begin{array}{l}\text { Does the patient } \\
\text { feel warm in the } \\
\text { extremities? }\end{array}$ & $\begin{array}{l}\text { Does the patient have dry mouth, bleeding } \\
\text { gums, fetid breath, acne and/or redness in } \\
\text { the skin, abdominal pain, microhematuria, or } \\
\text { itching? }\end{array}$ \\
\hline Mean & $\begin{array}{l}\text { Insufficient daily bowel } \\
\text { movements can mean } \\
\text { Blood deficiency.* }\end{array}$ & $\begin{array}{c}\text { This could be a symptom } \\
\text { of Qi deficiency. }\end{array}$ & $\begin{array}{c}\text { Commonly, this is a sign of } \\
\text { Yang deficiency. }\end{array}$ & $\begin{array}{c}\text { Commonly a sign of Yin } \\
\text { deficiency. }\end{array}$ & Commonly this is a sign of Heat re \\
\hline
\end{tabular}

*Blood deficiency can be understood as anemia in the energy level. As Blood deficiency may take years to appear in the laboratory exams, the patient with constipation and a normal complete blood count (CBC) can still be considered a patient with Blood deficiency, per TCM based on the symptoms he/she may present. 
medicine perspectives. The body and therefore, the possible treatments, is not only physical and constituted by organs and tissues. It is formed by energy. In Figure 10, a metaphor of Yin and Yang as the different kinds of medicine was created by the author. Nowadays, these two perspectives are separated, but they can be complementary [14-16].

Traditional Chinese medicine can be considered Yang energy, and Western medicine is considered Yin energy, already materialized. In the same way as the relationship between Yin and Yang, Traditional Chinese Medicine starts where Western Medicine ends, and vice-versa [14-16].

\section{Conclusion}

To treat patients with oligospermia is important to seek the problem at the energy level. In this study, it was demonstrated that patients with oligospermia have low energy on the chakras and the treatment of these deficiencies is important to achieve better result.

\section{Acknowledgments}

A special thank for Sandro C. Esteves (MD \&amp; Ph.D. in andrology and human reproduction, Androfert Reproduction Clinic, Campinas, São Paulo, Brazil), for the early development of this study in 2007.

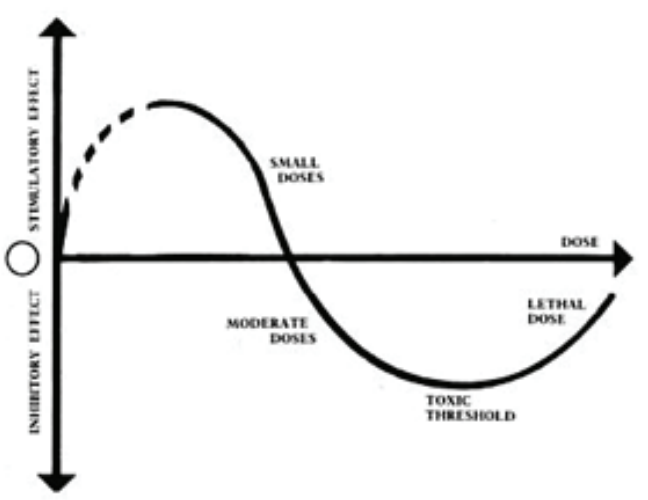

Figure 9: Arndt-Schultz Law.

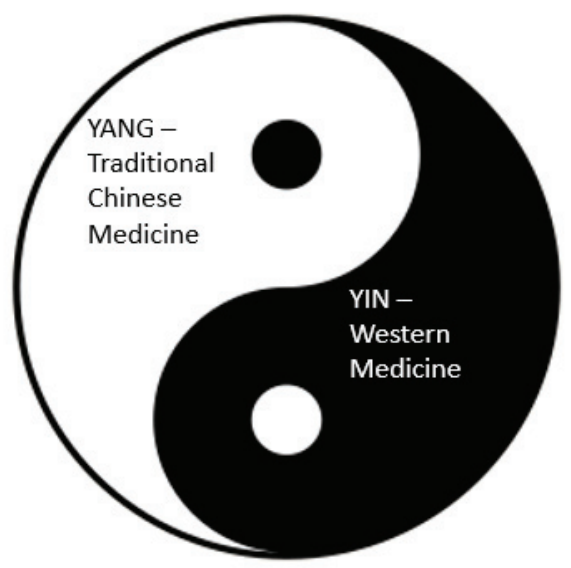

Figure 10: Traditional Chinese Medicine and Western Medicine - Yin and Yang Metaphor.

\section{References}

1. Punjab OM, Poolamets, Paju P, Vihljajev V, Pomm K, et al. (2017) Causes of male infertility: a 9-year prospective monocentric study on 1737 patients with reduced total sperm counts. Hum Reprod 32: 18-31. Link: https://bit.ly/2xMjanu

2. Campbell's Urology, $5^{\text {th }}$ Edition, Spanish edition 684

3. II Brazilian Consensus (2003) Male Infertility, São Paulo. 55

4. McLachlan RI (2013) Approach to the patient with oligozoospermia. J Clin Endocrinol Metab 98: 873-880. Link: https://bit.ly/2XbQAGK

5. Wang SC, Wang SC, Li CJ, Lin CH, Huang HL, et al. (2018) The Therapeutic Effects of Traditional Chinese Medicine for Poor Semen Quality in Infertile Males. J Clin Med 7: 239. Link: https://bit.ly/2ymNCoz

6. Zhou SH, Deng YF, Weng ZW, Weng HW, Liu ZD (2019) Traditional Chinese Medicine as a Remedy for Male Infertility: A Review. World J Men's Health 37 175-185. Link: https://bit.ly/2RagfvY

7. Hu M, Zhang Y, Ma H, Ng EH, Wu XK (2013) Eastern medicine approaches to male infertility. Semin Reprod Med 31: 301-310. Link: https://bit.ly/3aFJOgy

8. Ling HW (2019) Can We Treat Atopic Dermatitis without using Corticosteroids? J Pediatr Infants 2: 8-19.

9. Lomboy JR, Coward RM (2016) The Varicocele: Clinical Presentation, Evaluation, and Surgical Management. Semin Intervent Radiol 33: 163-169. Link: https://bit.ly/2X5c7kH

10. Ling HW (2018) Can Recurrent Furunculosis be Treated without the Use of Antibiotics? Acta Scientific Microbiology 1: 4-12. Link: https://bit.ly/2JCtGAB

11. Ling HW (2018) Could Postsurgical Nosocomial Cellulitis be Treated without the Use of Antibiotics? Acta Scientific Microbiology 1: 9. Link: https://bit.ly/2R9vbuh

12. Huang WL (2018) Can Hospital Osteomyelitis Be Treated Without the Use of Antibiotics?. Int J Microbiol Infect Dis 2: 1-6. Link: https://bit.ly/2X5SxVu

13. Huang WL (2018) The Treatment of Asthma Based on Traditional Chinese Medicine and Homeopathy. J Pediatr Infants 1: 23-27. Link: https://bit.ly/2R935PH

14. Ling HW (2019) Why Are Diabetic Patients Still Having Hyperglycemia despite Diet Regulation, Antiglycemic Medication, and Insulin? Int J Diabetes \& Metabolic Disorders. Link: https://bit.ly/3dUjnpA

15. Huang WL (2019) Is It Possible to Treat Giant Congenital Hairy Melanocytic Nevus Clinically? J Clin Case Rep Trials 2: 6-13. Link: https://bit.ly/2X46T8F

16. Ling HW (2019) Is it Possible to Treat Community-Acquired and Nosocomial Infections with the Same Method, Without the Use of Antibiotics? J App Microb Res 2: 1-13. Link: https://bit.ly/2xLL2Im

17. OuYang B, Zhen GU (1996) Essentials of Traditional Chinese Medicine. Translated by Lu Yubin. Beijing, China. Ed. Shan- dong Science and Technology Press.

18. Ni HC, Ching I () The book of Changes and the Unchanging Truth.

19. Ni M () The Essential Text of Chinese Health and Healing: The Yellow Emperor Classic of Medicine. Shambala Editor.

20. Chase CR (2018) The Geometry of Emotions: Using Chakra Acupuncture and 5-Phase Theory to Describe Personality Archetypes for Clinical Use. Med Acupunct 30: 167-178. Link: https://bit.ly/2JBFqTW 
21. Korotkov K (2005) The Scientific Basis of Integrative Medicine. Evid Based Complement Alternat Med 2: 425-426. Link: https://bit.ly/2JCoiOa

22. Zhu J, Arsovska B, Kozovska K (2018) Acupuncture Treatment for Fertility. Open Access Maced J Med Sci 6: 1685-1687. Link: https://bit.ly/2X1DBHP
23. Coimbra O, Luz SA (2017) Sistema de Cristais de Oz. Coleção Sentido Oculto. Chiado Editora.
Discover a bigger Impact and Visibility of your article publication with

Peertechz Publications

\section{Highlights}

* Signatory publisher of ORCID

* Signatory Publisher of DORA (San Francisco Declaration on Research Assessment)

* Articles archived in worlds' renowned service providers such as Portico, CNKI, AGRIS, TDNet, Base (Bielefeld University Library), CrossRef, Scilit, J-Gate etc.

* Journals indexed in ICMJE, SHERPA/ROMEO, Google Scholar etc.

* OAI-PMH (Open Archives Initiative Protocol for Metadata Harvesting)

* Dedicated Editorial Board for every journal

* Accurate and rapid peer-review process

* Increased citations of published articles through promotions

* Reduced timeline for article publication

Submit your articles and experience a new surge in publication services

(https://www.peertechz.com/submission).

Peertechz journals wishes everlasting success in your every endeavours.

Copyright: () 2020 Ling HW. This is an open-access article distributed under the terms of the Creative Commons Attribution License, which permits unrestricted use distribution, and reproduction in any medium, provided the original author and source are credited. 